\title{
The Impact of Basil Seed Gum on Native and Pregelatinized Corn Flour and Starch Gel Properties
}

\author{
Lara Matia-Merino ${ }^{1 *}$, Montse Prieto ${ }^{2}$, Laura Roman $^{2} \&$ Manuel Gómez ${ }^{2}$

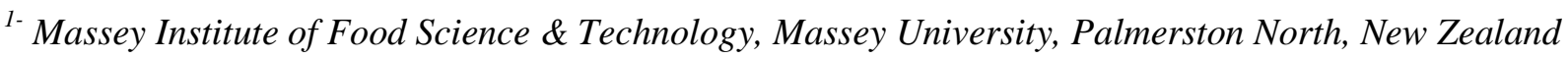 \\ ${ }^{2-}$ Food Technology Area, College of Agricultural Engineering, University of Valladolid, Palencia, Spain, \\ * Current contact information for Corresponding Author:
}

Lara Matia-Merino

E-mail: 1.matia-merino@massey.ac.nz

\begin{abstract}
The effect of Basil Seed Gum (BSG) on native and pre-gelatinized corn starch and flour gels was evaluated. With this purpose, the hydration, pasting, rheological, textural and microstructural properties of the mixed gels were analyzed. Xanthan was used as a comparison, as it presents comparable high zero shear viscosity to BSG. The presence of BSG led to greater water binding capacity and greater water absorption index of the starch and flours compared to the free-gum systems. In general BSG substantially increased the peak and final viscosities of the pastes, also leading to a raise in the viscoelasticity $\left(G^{\prime}\right.$ and $\left.G^{\prime \prime}\right)$ and hardness of the final gels, native or treated (pregelatinized starch and extruded flour). A more opened microstructure-compared to a homogeneous and dense matrix of the control native starch gels - with strands and a spider-like network of BSG across the pockets was detected. On the other hand, xanthan showed the opposite effect, decreasing the peak and final viscosities of the native systems, delaying the gelatinization process, and also leading to weaker gels of reduced viscoelasticity with opened honeycomb-like microstructures. However, for pregelatinized flour and starch the effect of xanthan was minimal.
\end{abstract}

Keywords: Basil seed gum, xanthan, extruded flour, starch, rheology, environmental scanning electron microscopy 


\section{Introduction}

Seed gums such as locust bean, tara or guar gum, are frequently used in the food industry. Less commonly used as food additives, but on the rise for the past decade given the research interest received, are mucilages from other seeds, such as flaxseed (Jun, et al., 2016), chia seeds (Goh, et al., 2016; Moreira, Chenlo, \& Torres, 2013), cress seeds (Naji, Razavi, \& Karazhiyan, 2013), sage seeds (Razavi, Alghooneh, Behrouzian, \& Cui, 2016; Razavi, Taheri, \& Quinchia, 2011), balangu seeds and basil seeds amongst others.

Basil seed gum (BSG) is a novel food polysaccharide extracted from Ocimum basilicum L. seeds and mainly composed of glucomannan (43\%), (1-4)-linked xylan (24.3\%), a minor fraction of highly branched arabino-galactan along with glucan (2.31\%), with a small fraction of protein $(1.32 \% \mathrm{wt} / \mathrm{wt})$ and a typical uronic acid content between $12.1-19.5 \%$ which provide the polyelectrolyte behavior to the extract (Anjaneyalu \& Channe Gowda, 1979; Azuma \& Sakamoto, 2003). It has promising stabilizing, emulsifying and foaming properties (HosseiniParvar, 2009; Hosseini-Parvar, Matia-Merino, Goh, Razavi, \& Mortazavi, 2010; Naji-Tabasi \& Razavi, 2016; Osano, Hosseini-Parvar, Matia-Merino, \& Golding, 2014) and has been used to modify the structure of processed cheese (Hosseini-Parvar, Matia-Merino, \& Golding, 2015), ice cream (BahramParvar \& Goff, 2013) and only recently of bread (Dorani, Ghavidel, Davoodi, \& Ghavidel, 2016).

Gums have been used in various bakery products, such as cakes (Gomez, Ronda, Caballero, Blanco, \& Rosell, 2007) and tortillas (Gurkin, 2002) to modify the cake batter viscosity and increase moisture retention in the final product. In the last years, their use has also increased in frozen dough as well as in standard, prebaked and gluten-free breads (Gallagher, Gormley, \& Arendt, 2004; Cristina M. Rosell \& Gomez, 2007; C.M. Rosell, Rojas, \& de Barber, 2001).

Generally, in bakery products as well as in many pastry fillings, hydrocolloids interact with flours and starches modifying their pasting, thermal and rheological properties affecting their production and the final product quality. This is the reason why their interactions are widely studied. However the effects depend greatly on the type of hydrocolloid (BeMiller, 2011) and in several occasions opposite effects have been found and therefore no clear mechanism has been established. So far, no information can be found in the literature dealing with the interactions 
between BSG and starch or flour in model systems. Only recently the effect of basil seed gum on the quality of wheat bread has been explored (Dorani, et al., 2016; Israr, et al., 2016).

Corn starch is the most common ingredient in commercial gluten free bread recipes and in many pastry fillings, whereas corn flour is normally used in the elaboration of polenta and many other Latin-American products (Pineda-Gomez, et al., 2012). After a hydrothermal treatment, applied via drum drying or extrusion (Doublier, Colonna, \& Mercier, 1986), isolated starch or starch present in flour can gelatinize forming pre-gelatinized starch or instant flour. The intensity of the extrusion treatment, determined by temperature, initial moisture content and screw speed, leads to various degrees of starch gelatinization and protein denaturation modifying flour functionality (Martinez, Calvino, Rosell, \& Gomez, 2014).

The objective of this work was to study the effect of BSG on corn starch or corn flour properties - native as well as pregelatinized - to observe potential interactions that could be key for future applications in carbohydrate-based products. With this purpose, water binding, pasting, rheological, textural and microstructural properties of the pastes and gels formed with the mixtures of these corn starch and corn flour powders and BSG (up to 2.5\% substitution) were measured. Additionally, xanthan gum, a commonly employed anionic polysaccharide, was used for comparison purposes as it exhibits a higher zero shear viscosity and yield stress comparable to BSG at similar concentration (Hosseini-Parvar, et al., 2010).

\section{Materials and Methods}

\subsection{Materials}

Native yellow corn flour ( $8.97 \%$ moisture, $4.58 \%$ protein, and pregelatinized (extruded) yellow corn flour (7.82\% moisture, $5.11 \%$ protein) were provided by Molendum Ingredients (Zamora, Spain). The extrusion treatment was performed with an industrial Bühler Basf single screw extruder (Bühler S.A., Uzwil, Switzerland). The length to diameter (L/D) ratio for the extruder was 20:1. The extrusion was carried out with a further water addition of $12 \%$ at a maximum barrel temperature of $160^{\circ} \mathrm{C}$, a feed rate of $500 \mathrm{~kg} / \mathrm{h}$ and a screw speed of $453 \mathrm{rpm}$. The extruded product was dried by convection air and then ground with a compression roller to the particle size specified above. 
Standard native corn starch $(10.72 \%$ moisture) and pregelatinized corn starch (PREGEFLO MM, 7.44\% moisture) were supplied by Roquette Laisa (Lestrem, France). Xanthan gum was provided by Danisco France SAS (Melle, France). Basil seeds were obtained from a local market at Isfahan city in Iran. The basil seed gum (BSG) was extracted according to the procedure of Hosseini-Parvar et al. (2010). The chemical composition of BSG based on dry basis (wt/wt) was: $1.32 \%$ protein, $6.53 \%$ ash, $4.38 \%$ fat, $79.63 \%$ total carbohydrate, $0.55 \%$ soluble sugars, $1.53 \%$ starch and $9.1 \%(\mathrm{wt} / \mathrm{wt})$ moisture content.

\subsection{Methods}

For all tests performed with the two gums, xanthan and BSG, two levels of substitution of either the flour or the starch were employed $(0.5 \%$ and $2.5 \%)$ and up to $5 \% \mathrm{wt} / \mathrm{wt}$ substitution in the case of the pasting test. The gums were pre-hydrated with water for $90 \mathrm{~min}$ at room temperature (or at $30^{\circ} \mathrm{C}$ for the pasting properties) and at a constant stirring speed in order to achieve sufficient hydration and a homogenous dispersion.

\subsubsection{Water Binding Capacity}

In order to evaluate the hydration properties of the powders, the water binding capacity (WBC), defined as the amount of water retained by the sample after it has been centrifuged, was measured as described in method 56-30 (AACC, 2012) with slight modifications (Martinez, Rosell, \& Gomez, 2014). For the control samples, the test was carried out by adding $25 \mathrm{~mL}$ of distilled water to $1.25 \mathrm{~g}( \pm 0.01 \mathrm{~g})$ of flour or starch. For the gum dispersions, the corresponding amounts for 0.5 and $2.5 \% \mathrm{wt} / \mathrm{wt}$ substitution were mixed previously with water and then either the starch or the flour were added to make up to $1.25 \mathrm{~g}$ before placing the mixture in Falcon tubes. Samples were centrifuged at $2000 \times \mathrm{g}$ for $10 \mathrm{~min}$.

\subsubsection{Water Absorption Index}

Water absorption index (WAI) was determined as described in an existing publication (Hera, Gomez, \& Rosell, 2013) with slight modifications. Firstly, when added, the corresponding amount of gum was pre-hydrated with $25 \mathrm{ml}$ of distilled water for $90 \mathrm{~min}$ at a constant magnetic stirring speed at room temperature. Then enough flour/starch was added to make up a total of $1.25 \mathrm{~g}$ of solids dispersed in $25 \mathrm{ml}$ of water using a $50 \mathrm{ml}$ Falcon tube. The mixtures were heated at $90^{\circ} \mathrm{C}$ for $10 \mathrm{~min}$ in a water bath. The cooked paste was cooled in an ice water bath for 
$10 \mathrm{~min}$ and then centrifuged at $3000 \times \mathrm{g}$ for $10 \mathrm{~min}$. The supernatant was decanted and the sediment was weighed $\left(\mathrm{W}_{\mathrm{r}}\right)$. WAI was calculated as follows:

$$
\text { WAI }(\mathrm{g} / \mathrm{g})=\mathrm{W}_{\mathrm{r}} / \mathrm{W}_{\mathrm{i}}
$$

where $\mathrm{W}_{\mathrm{i}}$ is the sample weight in dry basis.

\subsubsection{Pasting properties}

Pasting properties of native and pregelatinized flours and starches were determined in the presence and absence of gums using a Rapid Visco Analyser (RVA, Model RVA-4C, Newport Scientific Pty. Ltd.,Warriewood, Australia). Control samples were prepared by dispersing 3.5g $( \pm 0.01 \mathrm{~g})$ of flour or starch in $25 \mathrm{~g}( \pm 0.01 \mathrm{~g})$ of distilled water. For the mixed preparations, the gum was first mixed with the water in the aluminium canister at $160 \mathrm{rpm}$ at $30^{\circ} \mathrm{C}$ for $90 \mathrm{~min}$. The corresponding amounts of gums (0.5-5\%wt/wt substitution) were first hydrated after which, either the flour or starch were added up to a total of $3.5 \mathrm{~g}$ of mixed powder in $25 \mathrm{~g}$ of distilled water. The heating and cooling cycles were programmed following the general pasting method 61.02.01 (AACC, 2012) with slight modifications, ending the measurement at $30^{\circ} \mathrm{C}$. The slurry was held at $50^{\circ} \mathrm{C}$ for $1 \mathrm{~min}$, then heated to $95^{\circ} \mathrm{C}$ and held at that temperature for $2 \mathrm{~min} 30 \mathrm{~s}$. It was subsequently cooled to $30^{\circ} \mathrm{C}$ and held at that temperature for $4 \mathrm{~min}$.

\subsubsection{Gel preparation}

Gels were made in a beaker, adding starch/flour to the gum previously hydrated. The corresponding amount of gum was first dispersed in $200 \mathrm{~g}$ of distilled water for $90 \mathrm{~min}$ at room temperature. Then the required amount of flour/starch was added to this, to obtain a final $25 \mathrm{~g}$ of solids (or $12.5 \% \mathrm{wt} / \mathrm{wt}$ powder in solution). The mixture was then brought to boiling point and stirred at a constant speed. Samples were kept at approximately $95^{\circ} \mathrm{C}$ for $10 \mathrm{~min}$ after which, they were poured into four cylindrical plastic containers $(33.50 \mathrm{~mm}$ diameter and $16 \mathrm{~mm}$ height). Samples were left to rest at room temperature for 30min to cool down and then covered with parafilm to avoid drying and stored at $4^{\circ} \mathrm{C}$ for $24 \mathrm{~h}$ to achieve gel stabilization before texture tests.

\subsubsection{Gel texture}

The gels were removed from their moulds and textural properties were measured on the cold samples, using a TA.XT2i Texture Analyzer (Stable Micro Systems Ltd., Surrey, UK) with a 5kg load, equipped with Texture Expert version 1.0 for Windows. One compression cycle was 
applied using a 50mm-diameter cylindrical probe at a constant crosshead velocity of $0.5 \mathrm{~mm} \mathrm{~s}^{-1}$ to a sample depth of $5 \mathrm{~mm}$, followed by a return to the original position. The trigger force was $49 \mathrm{mN}$. Curves of force versus time were analyzed to calculate the values of the texture attributes: maximum force in compression (Fmax) or hardness, work in compression (Area + ) or consistency and work of adhesion (Area -) or adhesiveness.

\subsubsection{Rheological measurements}

All rheological measurements of the freshly prepared pastes were carried out using a rheometer (Haake RheoStress 1, Thermo Fischer Scientific, Scheverte, Germany) with a titanium parallel plate geometry sensor PP60 Ti $(60 \mathrm{~mm}$ diameter, and 1mm gap). The sample (prepared as in 2.2.3, but used before cooling) was placed into the rheometer calibrated at $50^{\circ} \mathrm{C}$ and covered with Panreac vaseline oil (Panreac Química S.A., Castellar del Vallés, Spain) to avoid drying.

Firstly a temperature sweep was carried out from $50^{\circ} \mathrm{C}$ to $30^{\circ} \mathrm{C}$ during $30 \mathrm{~min}$ to follow further development of the gel. The remaining tests were performed at a fixed temperature of $30^{\circ} \mathrm{C}$. A $2 \%$ strain within the linear region (previously determined) was used to perform a frequency sweep test in a range of $0.1-10 \mathrm{~Hz}$. The viscoelastic properties of the samples were quantified by measuring the storage or elastic modulus $\left(G^{\prime}\right)$, loss or viscous modulus $\left(G^{\prime \prime}\right)$, complex modulus $\left(G^{*}\right)$, and loss tangent $(\tan \delta)$.

\subsubsection{Environmental Scanning Electron Microscopy (ESEM)}

Gels prepared as described in 2.2.5 were freeze-dried (Alpha 1-2 LO plus, Christ, Osterode, Germany freeze-drier). Gel micrographs were taken with a Quanta 200FEI (Hillsboro, Oregon, USA) ESEM. Photomicrographs were taken in beam deceleration mode (BDM) at $1.5 \mathrm{keV}$ in high vacuum mode with a backscattered electron detector (BSED).

\subsubsection{Statistical Analysis}

Differences between the parameters for the gels were studied by analysis of variance (one-way ANOVA). Fisher's least significant difference (LSD) was used to describe means with $95 \%$ confidence intervals. The statistical analysis was performed using the Statgraphics Plus V5.1 software (Statpoint Technologies, Inc., Warrenton, USA). All of the tests above were performed in duplicates. 


\section{Results}

\subsection{Hydration Properties}

Fig.1 and Fig. 2 show the water binding capacity (WBC) and the water absorption index (WAI) values for all systems, respectively. From Fig. 1, it is clear that the pregelatinized products (starch and extruded flour) (Fig.1C,D) exhibited greater WBC values compared to the native products (Fig. 1A,B) due to the greater ability to bind water of gelatinized starch versus native starch, when dispersed in cold water. The higher water absorption and retention capacity of these flours has been established earlier (Hagenimana, Ding, \& Fang, 2006; Martinez, Oliete, Roman, \& Gomez, 2014); the loss of starch granule integrity that occurs during gelatinization in the extrusion process makes hydroxyl groups available to bind water molecules. For the non-treated (native) control samples, the flour showed greater values than starch (Fig. 1A,B) due the presence of protein which presents greater WBC compared to native starch as reported earlier (Pareyt \& Delcour, 2008). However, for the pregelatinized (control) products, the greater WBC of pregelatinized starch minimised these variations between starch and flour, and no significant differences could be detected (Fig. 1C,D).

Regarding the effect of the gums on the native systems, the incorporation of xanthan, did not modify the WBC, whereas BSG increased it though only at the highest level (2.5\%). In the case of pregelatinized starch (Fig. 1D), both xanthan and BSG increased substantially the WBC (between 10-12g water/g solids with gums versus $7 \mathrm{~g}$ water/g solids for starch alone). However, with the pregelatinized (extruded) flour (Fig. 1C), there was only a significant increase with BSG at the highest level, being this increase lower than the increase in the case of the pregelatinized starch. This could indicate that the presence of protein and the lower amount of starch present in the flours minimised the effect of the gums on the WBC. Previously, carrageenans and agar have been shown to increase the WBC of native flours without influencing the values for extruded flour (Martinez, Macias, Belorio, \& Gomez, 2015). From our results, it seems that the highest level of BSG increased the WBC in all systems, native or treated.

Water uptake during thermal treatment-which for flours involves starch gelatinization and protein denaturation — can be assessed by the water absorption index (WAI) (Fig. 2). The effect of the gums seemed mainly noticeable when mixed with native corn starch — and especially for xanthan (Fig. 2B) and for the highest concentration of BSG (2.5\%) mixed with the extruded flour 
(Fig. 2C). Thermal treatment did change the effect of xanthan; when hydrating in cold, xanthan only increased the WBC of pregelatinized starch, however when heated in the presence of native corn starch, xanthan had the greatest impact on the WAI, reaching values of up to $\sim 14 \mathrm{~g}$ wet residue/g solids at $2.5 \%$ xanthan versus $7.5 \mathrm{~g}$ for native starch alone (Fig. 2B). Like in the case of the WBC, BSG again increased the WAI in all cases at high concentration.

Previously, water absorption capacity of starch (measured in cold) has been shown to increase substantially in the presence of xanthan and guar gum (Nawab, Alam, \& Hasnain, 2014) or decreased slightly in the presence of pectin, konjac gum and hydroxypropylmethylcellulose (Varela, Navarro, \& Yamul, 2016). In general an increase in water affinity in the presence of the gum is expected due to the hydroxyl groups in the hydrocolloid structure which allows more hydrogen bonding. However, water competition between starch/protein and gum, possible gum/starch interactions, and the different cold/hot hydration properties of the gums and the starches may lead to different outcomes. This will be discussed in the final section after describing the effects of the gums on other relevant properties. 


\subsection{Pasting Properties}

The pasting properties of the flours and the starches in the presence of BSG and xanthan are shown

in

A
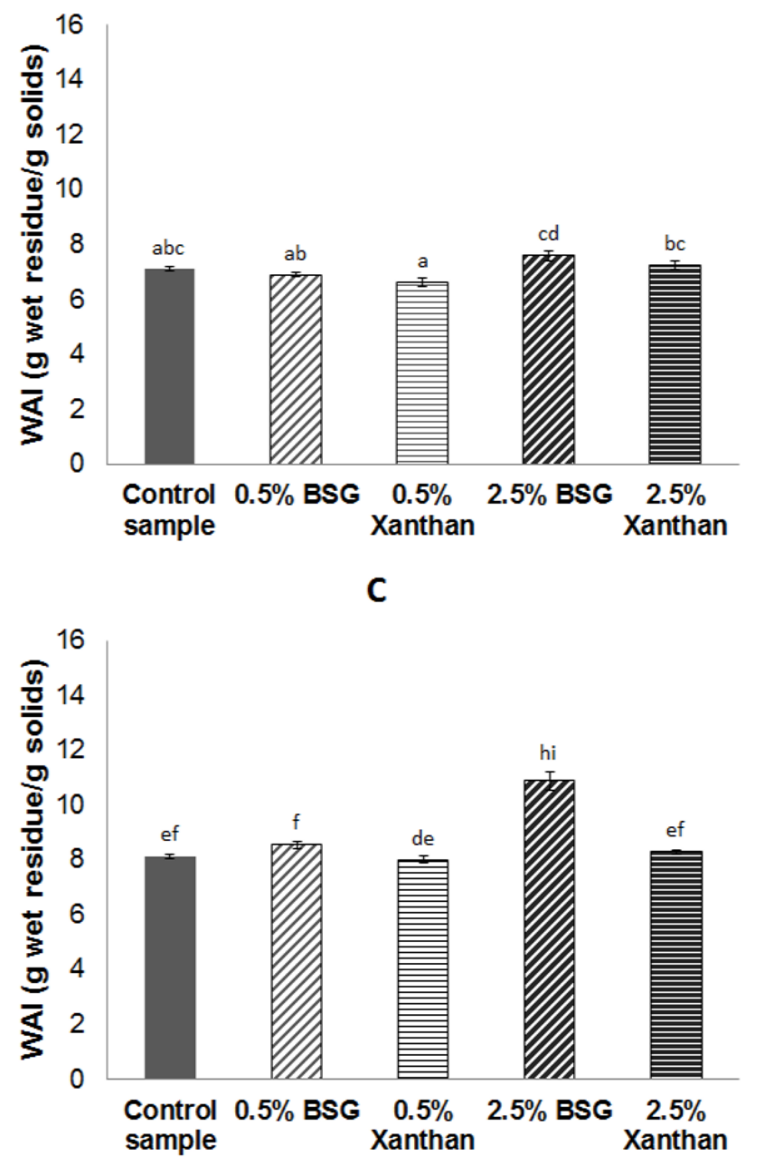

B

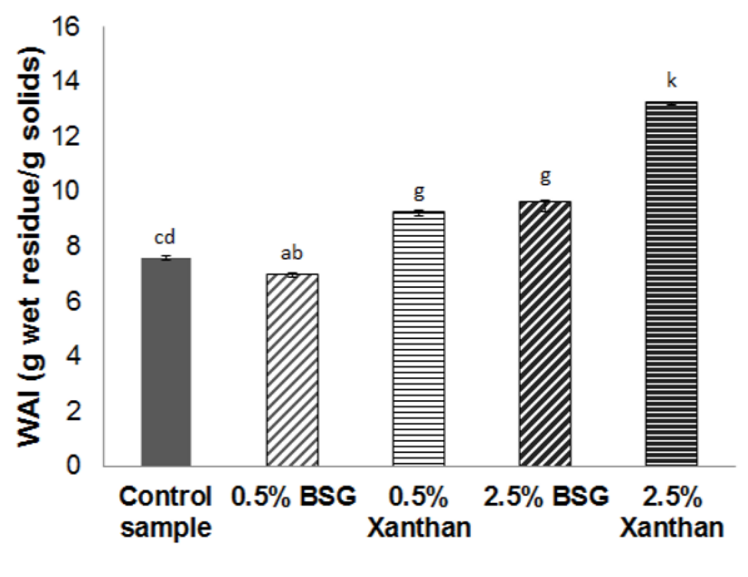

D

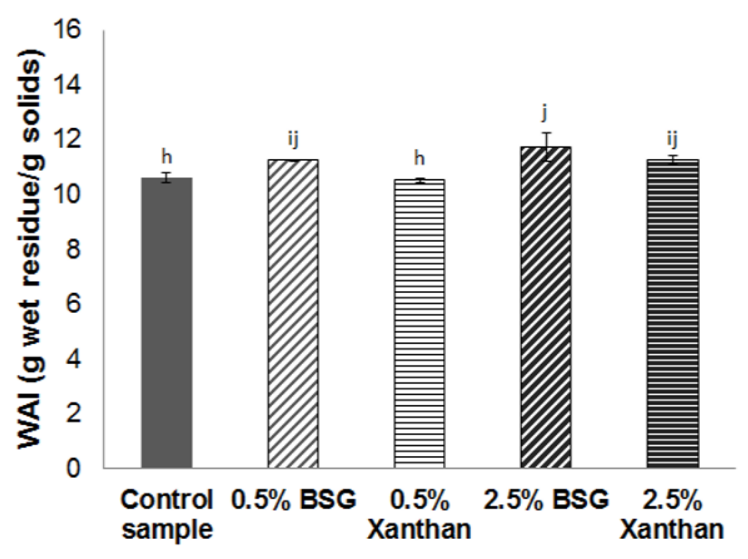


Fig. 3. The native systems (Fig. 3A,B) showed the typical viscosity profiles as the sample was heated and cooled, in agreement with corn starch pasting properties (Sandhu \& Singh, 2007). The peak viscosity (PV) and final viscosity (FV) values were greater for the starch versus the flour owned to the lower starch granules content responsible for the viscosity build-up. A striking difference between the effect of the two gums was observed in these native starch and flours (Fig. 3A,B); whereas BSG seemed to clearly have a synergistic concentration-dependent effect, by increasing the peak and final viscosities (i.e. PV increased from $\sim 3500$ to $6300 \mathrm{cP}$ for the control native flour and at 5\% BSG substitution, respectively), xanthan gum had a detrimental effect on the pasting properties - more pronounced for starch — decreasing the peak and final viscosities (i.e. FV decrease from $\sim 8820$ to $\sim 5000 \mathrm{cP}$ for the control native starch and at 5\% BSG substitution, respectively) and decreasing substantially the breakdown (BR) (Fig. 3B), indicating a more stable conformation/structure. This effect was independent on concentration above $2.5 \%$ xanthan, in the case of native starch. Whereas BSG did not seem to affect the gelatinization temperature, xanthan gum delayed it (i.e. from $76.4^{\circ} \mathrm{C}$ for native control starch to $85.65^{\circ} \mathrm{C}$ with $5 \%$ xanthan substitution). It is noteworthy that the gels at $5 \%$ BSG substitution were very strong, and in the latest stages of cooling the profiles became more irregular, probably due to the shearing of a broken gel, so the latest part of the curve has been eliminated as it is not representative of the final developed viscosity.

As expected, the viscosity development of the extruded flour and pregelatinized starch (Fig. 3C,D) did not follow the typical pronounced gelatinization peak, and showed much lower viscosity values (and slightly more irregular profiles) compared to the native systems in agreement with previous work (Martinez, et al., 2015). These starches and flours start thickening up as soon as they contact water developing an instant or cold viscosity. In extruded flour, the highest values for PV are associated with a high proportion of ungelatinized starch, whereas the lowest values of PV indicate that the starch has been gelatinized and dextrinized in high proportion as a result of the processing conditions (Jongsutjarittam \& Charoenrein, 2014; Ornpicha \& Sanguansri, 2014). This could be the reason why purely gelatinized starch (Fig. 3D) showed no peak viscosity but only a decrease in viscosity with heating and the viscosity curves were also lower compared to the extruded flours. In the presence of the gums, BSG raised the viscosity of the paste as soon as it contacted the starch or flour at concentrations above $0.5 \%$, 
before any heating was applied. Then, as in the case of the native systems, the viscosity developed increased under cooling (substantially at 5\% BSG substitution) generating FV between 3900-4200cP compared to the controls (1500-900cP) for both flour and starch. In the case of xanthan, contrary to the native systems, the viscosity did not decrease; either remained similar to the control at low concentration or increased with heating and then further cooling reaching comparable values to BSG at $2.5 \%$ substitution, with no further increase above this concentration. None of the gums on their own developed viscosity with the heating/cooling cycle (data not shown).

Our results agree with Israr et al (2016) as the PV and FV of wheat flour increased with BSG concentration, though the effects shown for corn flour and starch are more pronounced for similar levels of substitution. It is likely that the presence of gluten plays an important role on the interactions with the starch granules, and in its absence, the effect of BSG is very pronounced as in the case of our native corn flour and starch. Also recently, another glucomannan-which is also the major fraction of BSG-konjac gum, has been shown to increase the peak viscosity of mixed potato/wheat starch on its pasting profile (Varela, et al., 2016). Possible explanations of this rise in peak viscosity deal with the interactions between amylose leached and the gum, resulting in stronger networks (Correa, Ferrero, Puppo, \& Brites, 2013) upon heating, and an increase in the effective concentration of polysaccharides due to depletion of water in the continuous phase as the starch gelatinises (Chaisawang \& Suphantharika, 2006). On the other hand, mixed effects have been reported for xanthan gum depending on the type of starch studied (Achayuthakan \& Suphantharika, 2008; Chen, Fang, Zuo, \& Liu, 2016). However for corn starch, the addition of xanthan has been shown to decrease the PV, the BR and the retrogradation (Weber, Clerici, Collares-Queiroz, \& Chang, 2009) in agreement with our results. These authors attributed these effects to a delay in granule swelling that could also account for the much reduced setback, i.e. less time for mobilization of amylose /a restriction in amylose leaching out. In general, explanations based on depletion flocculation effects promoted by the rigid xanthan gum chains, formation of a biphasic system with the gum located in the continuous phase increasing the viscosity, and the wrapping of the starch granules by the gum-leading to a lower degree of rupture of the granules, have been offered to explain the various effects observed on the pasting properties (BeMiller, 2011). 


\subsection{Rheological properties of the gels}

The mixed pastes were placed on the rheometer at $50^{\circ} \mathrm{C}$ and cooled down at $30^{\circ} \mathrm{C}$ following the development of the viscoelasticity without disturbing the gel network formation. An example of this temperature sweep carried out for all the samples can be found in Fig. 2A where the steady increase of the elastic $G^{\prime}$ and viscous modulus $G^{\prime}$ for the native starch was observed for the remaining of the systems (data not shown). In all of them, the elastic component was above the viscous component showing the already formed network in the still flowing paste at $50^{\circ} \mathrm{C}$ placed in the rheometer which became a set gel under cooling.

The frequency sweep tests carried out at $30^{\circ} \mathrm{C}$ showed very steady $G^{\prime}$ and $G$ " values typical of set gels, very parallel to the frequency axis denoting their frequency independency (Fig. 2B). Only the values at $1 \mathrm{~Hz}$ of the complex modulus which encompasses both elastic and viscous components are plotted in Fig. 2C-F for comparison purposes. The native flour and starch networks showed greater viscoelasticity (much greater elasticity or higher $\mathrm{G}^{\prime}$ values driving higher $\mathrm{G}^{*}$ moduli) compared to the extruded flour or pregelatinized starch with lower gel strength values $\left(G^{*}\right)$ (i.e. $\sim 4000 \mathrm{~Pa}$ and $750 \mathrm{~Pa}$ for native and pregelatinized starch, respectively). In general starch gels were stronger than the flour gels as the presence of protein and the lower starch content in the flour results in slightly weaker gels (i.e. $750 \mathrm{~Pa}$ and $500 \mathrm{~Pa}$ for the pregelatinized starch and extruded flour, respectively). In addition it is possible that starch dextrinization occurring in the extruded flour may be responsible for the weak texture of its gels (Yousif, Gadallah, \& Sorour, 2012).

Clearly the incorporation of the highest amount of BSG gum $(2.5 \% \mathrm{wt} / \mathrm{wt})$ resulted in the strongest gels in all cases, native or pregelatinized systems, improving the viscoelastic properties with respect to the control samples as opposed to $2.5 \%$ xanthan gum, which either had a minimal effect on the pregelatinized flour and starch or decreased by half the strength of the native systems (i.e. $\sim 3000 \mathrm{~Pa}$ for control-native flour versus $\sim 1500 \mathrm{~Pa}$ for native flour substituted with $2.5 \%$ BSG). Also clearly a certain amount of gum is really needed in the case of BSG to observe the synergistic effect, since the presence of $0.5 \% \mathrm{wt} / \mathrm{wt}$ was insufficient to increase the viscoelasticity of the gels - either had no effect (extruded flour and pregelatinized starch) or decreased the value of the modulus (native flour and starch). It is also noteworthy that the 
extruded flour was the system where the presence of the gums had less impact on the properties of the final gels. All this in agreement with the results obtained from the pasting curves above. Contradictory data regarding viscoelasticity can be found in the literature, depending on the type of starch and probably the way the gels were prepared. The addition of up to $3 \%$ hydrocolloids such as pectin, HPMC, gum Arabic and konjac gum has been shown to decrease the $G$ ' and $G$ " values of wheat/potato starch gel mixtures (Varela, et al., 2016). Earlier, the presence of xanthan, as in the present case, has been shown to reduce the gel strength of corn starch in agreement with an inhibition of the formation of a strong network probably due to coating of starch by xanthan, also substantially reducing starch retrogradation (Christianson, 1982). Later on, a more rapid initial increase in gel firmness, but a decrease in firmness and elastic behavior upon extended storage was also found for maize starch+ xanthan systems (Alloncle \& Doublier, 1991). Subsequent studies have also reported an increase of $G$ ' values, with the addition of guar and xanthan gum to tapioca starch (Chaisawang, et al., 2006) or to waxy corn starch (Achayuthakan, et al., 2008).

\subsection{Textural properties of the gels}

Regarding the textural properties of gels measured by large deformation, it can be observed from Table 1 that the gels made up from native starch and flour presented greater hardness and consistency (peak and area) compared to the pregelatinized systems (made up from starch and extruded flour). Whereas the addition of xanthan clearly reduced the gel strength in the native flour and starch gels, BSG increased it, being the effect more pronounced in both cases with increasing amount of gum, generally agreeing with the small deformation oscillatory dynamic tests (Fig. 4). In the case of pregelatinized starch and flour, the incorporation of BSG had also a substantial effect on increasing the strength of the resulting gels, whereas xanthan gum either did not modify the gel texture (extruded flour gels) or decreased slightly the gel strength (pregelatinized starch gels).

The textural properties of rice starch gels including hardness, adhesiveness and chewiness have been shown not to be affected by the addition of $0.4 \%$ konjac glucomannan (Huang, Kennedy, $\mathrm{Li}, \mathrm{Xu}, \& \mathrm{Xie}, 2007)$. However an increase in hardness with increasing concentration of konjac has been reported in gels with native and pregelatinized cassava (Shanavas, Moorthy, Sajeev, 
Misra, \& Sundazeem, 2010). On the other hand, the addition of xanthan has been shown to increase the initial storage young modulus of tapioca starch gels but to retard the retrogradation of the gels, leading to less firmer and brittle gels compared to pure starch gels over a cold storage period (Pongsawatmanit, Chantaro, \& Nishinari, 2013). Also the presence of xanthan seems to lead to softer wheat starch gels (Seetapan, et al., 2013). Overall, the results found here would be in agreement with a weakening of the gels in the presence of xanthan and with a strengthening of the gels in the presence of BSG.

\subsection{Microstructural properties of the gels}

The microstructures of the native starch gel or native starch+gum mixed gels are shown in Fig. 5. Purely starch gel showed a very homogeneous and dense matrix structure containing small pores (Fig. 5A, B). Similar SEM porous/spongy-like structures have been observed earlier in corn starch pastes and gels (Han \& Hamaker, 2000). However, the inclusion of gums yielded a different gel appearance; the presence of $2.5 \%$ gums resulted in a heterogeneous structure made up of big pockets where strands and spider-like network of BSG across the pockets were noticeable (arrows in Fig 5D-F), with the presence of xanthan resulting in an order honeycomblike microstructure with bigger cells and very smooth cell walls (Fig. 5G-I). Apart from strands, globular particles of around 3-5 $\mathrm{m}$ were detected in the freeze-dried BSG powder (Fig. 5C), indicating the presence of both particles and strands in this gum as reported earlier by other authors (Rafe, Razavi, \& Farhoosh, 2013).

The various structures observed here can be associated with differences in water mobility and rearrangement of starch molecules under storage conditions. Thus, in previous work, the presence of konjac glucomannan-with similar structure to BSG, was effective at retarding retrogradation of starch acting as a physical barrier to prevent amylopectin chain association during storage (Sanguansri, Orawan, Kategunya, \& Masubon, 2011; Schwartz, et al., 2014). Meanwhile xanthan gum has also been shown to decrease long term retrogradation (Muadklay \& Charoenrein, 2008). Therefore, in our case, the starch gels with a more open microstructure in the presence of both gums, would appear to be less retrograded. Additionally, the fact that the water absorption index increased considerably with both gums (Figure 2B), and especially with xanthan gum, could also account for this change in the gel structure, and could be related to a 
faster/better water immobilization that may then difficult water diffusion during storage and, rearrangement of starch molecules.

\section{General Discussion}

The way the starch-hydrocolloid gel is prepared as well as how the non-starch polysaccharide is added (substitution/addition) influences the gel properties and can account for the opposite effects of specific hydrocolloids often found in literature (BeMiller, 2011; Mandala \& Bayas, 2004). In the present study, both hydrocolloids added by substitution were hydrated before mixing with the starch or flour so full polysaccharide functionality is expected.

Both xanthan and BSG are anionic polysaccharides, shear thinning and present comparable high zero-shear viscosities. The viscosity of xanthan decreases with temperature - attributed to a conformational transition of xanthan chains from helical at low temperatures to random coil at high temperatures (Paoletti, Cesaro, \& Delben, 1983) and upon cooling, the higher xanthan concentrations behave like gels characterized by a storage shear modulus $\left(G^{\prime}\right)$ larger than the loss modulus $\left(G^{\prime \prime}\right)$. The rotational viscosity of BSG also decreases with temperature up to $60^{\circ} \mathrm{C}$, with a tendency to increase at higher temperatures (Hosseini-Parvar, et al., 2010). In fact, dynamic oscillatory testing has shown that BSG can form a thermo-reversible gel when cooling to $20^{\circ} \mathrm{C}$ after a heating phase (from 20 to $90^{\circ} \mathrm{C}$ ) (Rafe \& Razavi, 2013). This may account for the synergistic/network strengthening effect observed on the starch and flour gels, however interactions with starch are also likely to be responsible for the final result. Clearly, the interaction of xanthan gum is very different based on the detrimental effects on viscosity development and gel strength observed here. It is important to emphasize that none of the gums on their own built up a set gel network under shear after a heating/cooling cycle at the concentrations used here.

In general, the hydration properties of all systems, native or treated, in cold (WBC) or after heating (WAI), were increased in the presence of a high level of BSG (2.5\%). The starch gelatinization process is restricted if starch granules have restricted access to water due to the

gum competing for available water affecting the development of viscosity during pasting. Even if the gelatinization temperature was slightly increased in the presence of the gums, as detected by DSC, the peak and final pasting viscosities were enhanced in the presence of BSG; likely reasons 
for this can be possible interactions with amylose being leached (Funami, et al., 2005) and with low molecular weight amylopectin fractions in the paste (Weber, et al., 2009) and/or due to aggregation of BSG itself upon heating. This viscosity enhancement occurred in all systems, with native or pregelatinized starch, resulting in stronger gels with greater viscoelasticity and a connected network of BSG strands and particles across a more open starch matrix. On the other hand, xanthan restricted the peak viscosity, reducing also the final viscosity (resulting in weaker gels) in the native starch and flour pasting profiles, with the native starch presenting the greatest water absorption of all systems and a very different microstructure - open and with big cavities. The effect of xanthan has been explained earlier by the ability of xanthan molecules to associate and coat the starch granule surface, restricting starch swelling and gelatinization (Gonera \& Cornillon, 2002; Mandala, et al., 2004; Tester \& Sommerville, 2003). Also a negative impact on amylose-amylose interactions is possible, leading to a weakening of the final gel. Competition for the free water in the presence of this gum can also be responsible for the observed effects as indicated by Weber, et al., (2009), probably impacting the WAI, that for native starch + xanthan was significantly increased. The fact that in the presence of xanthan, not a detrimental effect but more of a slight viscosity enhancement occurred with the extruded flour and pregelatinized starch, reinforces the idea that the restriction effect happens as the starch granules gelatinize and this is not perceived if the system is already gelatinized. In fact, the resulting gels showed minimal textural and rheological changes in the presence of xanthan when compared to the controls.

It is also noteworthy that in the flour systems, the presence of corn protein: (i) could give rise to potential interactions between the gums and the proteins or (ii) the gums could hinder proteinstarch interactions as reported for gluten-starch systems in the presence of xanthan or alginate (Davidou, LeMeste, Debever, \& Bekaert, 1996). It seems that for flours (and especially the extruded flour) the impact of the gums on the viscoelasticity and texture of the final gels was reduced, which seems to indicate that in the presence of protein (denatured after the extrusion process) and with already gelatinized starch, a higher gum concentration would be required to obtain stronger networks when using BSG. However, BSG seemed to have a great effect on increasing the viscosity of pregelatinized starch and extruded flour without heating, as observed previously for similar flours when adding carrageenan and agar (Martinez, et al., 2015). Xanthan 
however did not change the viscosity of extruded flour before applying heating — this may have practical implications.

Finally, when analyzing the mechanical properties of more complex systems involving flour, such as bread, where both protein and starch are responsible for the development of the network, the effect of the hydrocolloid is highly influenced by the water absorption capacity during kneading. In the case of BSG, the high water retention of this gum and its possible interaction with starch indicate its potential for bread making.. BSG can also be of high interest as a gluten substitute and it is worth to explore the optimum dough hydration conditions in the presence of this gum for future work.

\section{Conclusion}

Even though the bulk viscosity provided by these two gums is comparable, xanthan gum and BSG showed opposite behavior in the pasting and gelation properties of native and pregelatinized (hydrothermally treated) starch and flour, yielding different gel microstructures. The incorporation of BSG resulted in the strongest gels in all cases, native or pregelatinized systems improving the viscoelastic properties by probably reinforcing the starch network under heating. Potential interactions with amylose/amylopectin and aggregation of BSG under heating are possible. On the other hand, xanthan gum either had a minimal effect on the pregelatinized flour and starch gels or substantially decreased the viscoelasticity and strength of the native gels by probably restricting starch gelatinization by coating the starch granules or/and affecting amylose interactions in the final network.

\section{Acknowledgements}

The authors acknowledge the financial support of the Spanish Ministry of Economy and Competitiveness (Project AGL2014-52928-C2-2-R) and the European Regional Development Fund (FEDER). The authors also acknowledge Dr. Sina H. Hosseini-Parvar for the extraction of the Basil Seed Gum used in this study. Laura Román would like to thank pre-doctoral fellowship from University of Valladolid 


\section{References}

Achayuthakan, P., \& Suphantharika, M. (2008). Pasting and rheological properties of waxy corn starch as affected by guar gum and xanthan gum. Carbohydrate Polymers, 71(1), 9-17.

Alloncle, M., \& Doublier, J. L. (1991). Viscoelastic properties of maize starch hydrocolloid pastes and gels. Food Hydrocolloids, 5(5), 455-467.

Anjaneyalu, Y. V., \& Channe Gowda, D. (1979). Structural studies of an acidic polysaccharide from ocimum bacilicum seeds. Carbohydrate Research, 75, 251-256.

Azuma, J., \& Sakamoto, M. (2003). Cellulosic hydrocolloid system present in seed of plants. Trends in Glycoscience and Glycotechnology, 15(81), 1-14.

BahramParvar, M., \& Goff, H. D. (2013). Basil seed gum as a novel stabilizer for structure formation and reduction of ice recrystallization in ice cream. Dairy Science \& Technology, 93(3), 273-285.

BeMiller, J. N. (2011). Pasting, paste, and gel properties of starch-hydrocolloid combinations. Carbohydrate Polymers, 86(2), 386-423.

Chaisawang, M., \& Suphantharika, M. (2006). Pasting and rheological properties of native and anionic tapioca starches as modified by guar gum and xanthan gum. Food Hydrocolloids, 20(5), 641-649.

Chen, T., Fang, S., Zuo, X. B., \& Liu, Y. M. (2016). Effect of curdlan and xanthan polysaccharides on the pasting, rheological and thermal properties of rice starch. Journal of Food Science and Technology-Mysore, 53(11), 4076-4083.

Christianson, D. D. (1982). Hydrocolloid interactions with starches. In G. E. I. D.R. Lineback (Ed.), Food carbohydrates (pp. 399-419). Westport, Conneticut AVI Publishing Co.

Correa, M. J., Ferrero, C., Puppo, C., \& Brites, C. (2013). Rheological properties of rice-locust bean gum gels from different rice varieties. Food Hydrocolloids, 31(2), 383-391.

Davidou, S., LeMeste, M., Debever, E., \& Bekaert, D. (1996). A contribution to the study of staling of white bread: Effect of water and hydrocolloid. Food Hydrocolloids, 10(4), 375-383.

Dorani, F., Ghavidel, R. A., Davoodi, M. G., \& Ghavidel, R. A. (2016). Effect of soybean meal and basil seed gum on physical and sensory quality of wheat bread. Advances in Food Sciences, 38(1), 14-21.

Doublier, J. L., Colonna, P., \& Mercier, C. (1986). Extrusion cooking and drum drying of wheat-starch .2. Rheological characterization of starch pastes. Cereal Chemistry, 63(3), 240-246.

Funami, T., Kataoka, Y., Omoto, T., Goto, Y., Asai, I., \& Nishinari, K. (2005). Effects of non-ionic polysaccharides on the gelatinization and retrogradation behavior of wheat starch. Food Hydrocolloids, 19(1), 1-13.

Gallagher, E., Gormley, T. R., \& Arendt, E. K. (2004). Recent advances in the formulation of gluten-free cerealbased products. Trends in Food Science \& Technology, 15(3-4), 143-152.

Goh, K. K. T., Matia-Merino, L., Chiang, J. H., Quek, R., Soh, S. J. B., \& Lentle, R. G. (2016). The physicochemical properties of chia seed polysaccharide and its microgel dispersion rheology. Carbohydrate Polymers, 149, 297-307.

Gomez, M., Ronda, F., Caballero, P. A., Blanco, C. A., \& Rosell, C. M. (2007). Functionality of different hydrocolloids on the quality and shelf-life of yellow layer cakes. Food Hydrocolloids, 21(2), 167-173.

Gonera, A., \& Cornillon, P. (2002). Gelatinization of starch/gum/sugar systems studied by using dsc, nmr, and cslm. Starch-Starke, 54(11), 508-516. 
Gurkin, S. (2002). Hydrocolloids - ingredients that add flexibility to tortilla processing. Cereal Foods World, 47(2), 41-43.

Hagenimana, A., Ding, X. L., \& Fang, T. (2006). Evaluation of rice flour modified by extrusion cooking. Journal of Cereal Science, 43(1), 38-46.

Han, X. Z., \& Hamaker, B. R. (2000). Functional and microstructural aspects of soluble corn starch in pastes and gels. Starch-Starke, 52(2-3), 76-80.

Hera, E. d. 1., Gomez, M., \& Rosell, C. M. (2013). Particle size distribution of rice flour affecting the starch enzymatic hydrolysis and hydration properties. Carbohydrate Polymers, 98(1), 421-427.

Hosseini-Parvar, S. H. (2009). Basil seed gum (bsg): Physico-chemical, rheological and emulsifying characterization and its synergistic interactions in combination with locust bean gum and guar gum. Unpublished Dissertation (Ph.D.), Ferdowsi University of Mashhad, Mashhad.

Hosseini-Parvar, S. H., Matia-Merino, L., Goh, K. K. T., Razavi, S. M. A., \& Mortazavi, S. A. (2010). Steady shear flow behavior of gum extracted from ocimum basilicum 1. Seed: Effect of concentration and temperature. Journal of Food Engineering, 101(3), 236-243.

Hosseini-Parvar, S. H., Matia-Merino, L., \& Golding, M. (2015). Effect of basil seed gum (bsg) on textural, rheological and microstructural properties of model processed cheese. Food Hydrocolloids, 43, 557-567.

Huang, M., Kennedy, J. F., Li, B., Xu, X., \& Xie, B. J. (2007). Characters of rice starch gel modified by gellan, carrageenan, and glucomannan: A texture profile analysis study. Carbohydrate Polymers, 69(3), 411-418.

Israr, T., Rakha, A., Rashid, S., Shehzad, A., Ahmed, A., \& Sohail, M. (2016). Effect of basil seed gum on physicochemical and rheological properties of bread. Journal of Food Processing and Preservation.

Jongsutjarittam, O., \& Charoenrein, S. (2014). The effect of moisture content on physicochemical properties of extruded waxy and non-waxy rice flour. Carbohydrate Polymers, 114, 133-140.

Jun, L., Youn Young, S., Jianheng, S., Yong, W., Supratim, G., \& Reaney, M. J. T. (2016). Variation of composition and functional properties of gum from six canadian flaxseed (linum usitatissimum 1.) cultivars. International Journal of Food Science \& Technology, 51(10), 2313-2326.

Mandala, I. G., \& Bayas, E. (2004). Xanthan effect on swelling, solubility and viscosity of wheat starch dispersions. Food Hydrocolloids, 18(2), 191-201.

Martinez, M. M., Calvino, A., Rosell, C. M., \& Gomez, M. (2014). Effect of different extrusion treatments and particle size distribution on the physicochemical properties of rice flour. Food and Bioprocess Technology, 7(9), 2657-2665.

Martinez, M. M., Macias, A. K., Belorio, M. L., \& Gomez, M. (2015). Influence of marine hydrocolloids on extruded and native wheat flour pastes and gels. Food Hydrocolloids, 43, 172-179.

Martinez, M. M., Oliete, B., Roman, L., \& Gomez, M. (2014). Influence of the addition of extruded flours on rice bread quality. Journal of Food Quality, 37(2), 83-94.

Martinez, M. M., Rosell, C. M., \& Gomez, M. (2014). Modification of wheat flour functionality and digestibility through different extrusion conditions. Journal of Food Engineering, 143, 74-79.

Moreira, R., Chenlo, F., \& Torres, M. D. (2013). Effect of chia (sativa hispanica 1.) and hydrocolloids on the rheology of gluten-free doughs based on chestnut flour. Lwt-Food Science and Technology, 50(1), 160-166.

Muadklay, J., \& Charoenrein, S. (2008). Effects of hydrocolloids and freezing rates on freeze-thaw stability of tapioca starch gels. Food Hydrocolloids, 22(7), 1268-1272.

Naji-Tabasi, S., \& Razavi, S. M. A. (2016). New studies on basil (ocimum bacilicum 1.) seed gum: Part iiemulsifying and foaming characterization. Carbohydrate Polymers, 149, 140-150.

Naji, S., Razavi, S. M. A., \& Karazhiyan, H. (2013). Effect of freezing on functional and textural attributes of cress seed gum and xanthan gum. Food and Bioprocess Technology, 6(5), 1302-1311.

Nawab, A., Alam, F., \& Hasnain, A. (2014). Functional properties of cowpea (vigna unguiculata) starch as modified by guar, pectin, and xanthan gums. Starch-Starke, 66(9-10), 832-840.

Ornpicha, J., \& Sanguansri, C. (2014). The effect of moisture content on physicochemical properties of extruded waxy and non-waxy rice flour. Carbohydrate Polymers, 114, 133-140.

Osano, J. P., Hosseini-Parvar, S. H., Matia-Merino, L., \& Golding, M. (2014). Emulsifying properties of a novel polysaccharide extracted from basil seed (ocimum bacilicum 1.): Effect of polysaccharide and protein content. Food Hydrocolloids, 37(0), 40-48.

Paoletti, S., Cesaro, A., \& Delben, F. (1983). Thermally induced conformational transition of xanthan polyelectrolyte. Carbohydrate Research, 123(1), 173-178.

Pareyt, B., \& Delcour, J. A. (2008). The role of wheat flour constituents, sugar, and fat in low moisture cereal based products: A review on sugar-snap cookies. Critical Reviews in Food Science and Nutrition, 48(9), 824-839. 
Pineda-Gomez, P., Acosta-Osorio, A. A., Coral, D. F., Rosales-Rivera, A., Sanchez-Echeverri, L. A., Rojas-Molina, I., \& Rodriguez-Garcia, M. E. (2012). Physicochemical characterization of traditional and commercial instant corn flours prepared with threshed white corn. Cyta-Journal of Food, 10(4), 287-295.

Pongsawatmanit, R., Chantaro, P., \& Nishinari, K. (2013). Thermal and rheological properties of tapioca starch gels with and without xanthan gum under cold storage. Journal of Food Engineering, 117(3), 333-341.

Rafe, A., \& Razavi, S. M. A. (2013). Dynamic viscoelastic study on the gelation of basil seed gum. International Journal of Food Science and Technology, 48(3), 556-563.

Rafe, A., Razavi, S. M. A., \& Farhoosh, R. (2013). Rheology and microstructure of basil seed gum and betalactoglobulin mixed gels. Food Hydrocolloids, 30(1), 134-142.

Razavi, S. M. A., Alghooneh, A., Behrouzian, F., \& Cui, S. W. (2016). Investigation of the interaction between sage seed gum and guar gum: Steady and dynamic shear rheology. Food Hydrocolloids, 60, 67-76.

Razavi, S. M. A., Taheri, H., \& Quinchia, L. A. (2011). Steady shear flow properties of wild sage (salvia macrosiphon) seed gum as a function of concentration and temperature. Food Hydrocolloids, 25(3), 451458.

Rosell, C. M., \& Gomez, M. (2007). Frozen dough and partially baked bread: An update. Food Reviews International, 23(3), 303-319.

Rosell, C. M., Rojas, J. A., \& de Barber, C. B. (2001). Influence of hydrocolloids on dough rheology and bread quality. Food Hydrocolloids, 15(1), 75-81.

Sandhu, K. S., \& Singh, N. (2007). Some properties of corn starches ii: Physicochemical, gelatinization, retrogradation, pasting and gel textural properties. Food Chemistry, 101(4), 1499-1507.

Sanguansri, C., Orawan, T., Kategunya, R., \& Masubon, T. (2011). Effect of konjac glucomannan on syneresis, textural properties and the microstructure of frozen rice starch gels. Carbohydrate Polymers, 83(1), 291296.

Schwartz, J. M., Le Bail, K., Garnier, C., Llamas, G., Queveau, D., Pontoire, B., Srzednicki, G., \& Le Bail, P. (2014). Available water in konjac glucomannan-starch mixtures. Influence on the gelatinization, retrogradation and complexation properties of two starches. Food Hydrocolloids, 41, 71-78.

Seetapan, N., Fuongfuchat, A., Gamonpilas, C., Methacanon, P., Pongjaruwat, W., \& Limparyoon, N. (2013). Effect of modified tapioca starch and xanthan gum on low temperature texture stability and dough viscoelasticity of a starch-based food gel. Journal of Food Engineering, 119(3), 446-453.

Shanavas, S., Moorthy, S. N., Sajeev, M. S., Misra, R. S., \& Sundazeem, A. S. (2010). Viscoelastic properties and excipient functionality of cassava starch and konjac glucomannan mixtures Trends in Carbohydrate Research, 2(1), 11-22.

Tester, R. F., \& Sommerville, M. D. (2003). The effects of non-starch polysaccharides on the extent of gelatinisation, swelling and alpha-amylase hydrolysis of maize and wheat starches. Food Hydrocolloids, 17(1), 41-54.

Varela, M. S., Navarro, A. S., \& Yamul, D. K. (2016). Effect of hydrocolloids on the properties of wheat/potato starch mixtures. Starch-Starke, 68(7-8), 753-761.

Weber, F. H., Clerici, M. T. P. S., Collares-Queiroz, F. P., \& Chang, Y. K. (2009). Interaction of guar and xanthan gums with starch in the gels obtained from normal, waxy and high-amylose corn starches. Starch-Starke, 61(1), 28-34.

Yousif, E. I., Gadallah, M. G. E., \& Sorour, A. M. (2012). Physico-chemical and rheological properties of modified corn starches and its effect on noodle quality. Annals of Agricultural Science (Cairo), 57(1), 87-96. 
Table 1. Textural properties of the gels made mixing starch/flour and gums (Xanthan/BSG)*

\begin{tabular}{|c|c|c|c|c|}
\hline \multicolumn{2}{|c|}{ Sample } & $\begin{array}{l}\text { Hardness } \\
(\mathrm{mN})\end{array}$ & $\begin{array}{l}\text { Consistency } \\
\text { (mN.seg) }\end{array}$ & $\begin{array}{l}\text { Adhesiv. } \\
\text { (mN.seg) }\end{array}$ \\
\hline \multirow[t]{5}{*}{ Native Starch } & Control & $8470^{f}$ & $28558^{g}$ & $141^{\mathrm{abcd}}$ \\
\hline & Xanthan $0.5 \%$ & $7442^{e}$ & $24385^{f}$ & $139^{\mathrm{abc}}$ \\
\hline & Xanthan $2.5 \%$ & $6303^{d}$ & $20942^{\mathrm{e}}$ & $143^{\mathrm{abcd}}$ \\
\hline & BSG $0.5 \%$ & $8274^{\text {ef }}$ & $26404^{\mathrm{fg}}$ & $136^{\mathrm{abc}}$ \\
\hline & BSG $2.5 \%$ & $11467^{\mathrm{hi}}$ & $35648^{j}$ & $98^{\mathrm{abc}}$ \\
\hline \multirow[t]{5}{*}{ Native Flour } & Control & $8713^{\mathrm{fg}}$ & $33622^{i}$ & $106^{\mathrm{abc}}$ \\
\hline & Xanthan $0.5 \%$ & $8457^{f}$ & $31742^{h}$ & $66^{\mathrm{a}}$ \\
\hline & Xanthan $2.5 \%$ & $6505^{d}$ & $23030^{f}$ & $165^{\mathrm{abcd}}$ \\
\hline & BSG 0.5\% & $9134^{\mathrm{g}}$ & $33067^{\mathrm{hi}}$ & $134^{\mathrm{abc}}$ \\
\hline & BSG $2.5 \%$ & $11836^{i}$ & $40749^{k}$ & $73^{a b}$ \\
\hline \multirow[t]{5}{*}{ Pregelat. Starch } & Control & $5424^{b c}$ & $17440^{d}$ & $174^{\mathrm{abcd}}$ \\
\hline & Xanthan $0.5 \%$ & $4990^{b}$ & $15673^{c}$ & $307^{\mathrm{ef}}$ \\
\hline & Xanthan $2.5 \%$ & $4202^{\mathrm{a}}$ & $13428^{a}$ & $492^{g}$ \\
\hline & BSG 0.5\% & $5618^{c}$ & $17158^{d}$ & $322^{\mathrm{ef}}$ \\
\hline & BSG $2.5 \%$ & $11201^{h}$ & $32911^{\mathrm{hi}}$ & $409^{f g}$ \\
\hline
\end{tabular}




\begin{tabular}{cl|lll}
\hline Extruded Flour & Control & $4361 \mathrm{a}$ & $14097 \mathrm{ab}$ & $189^{\mathrm{cd}}$ \\
& Xanthan 0.5\% & $4062^{\mathrm{a}}$ & $13240^{\mathrm{a}}$ & $160^{\mathrm{abcd}}$ \\
Xanthan 2.5\% & $4324^{\mathrm{a}}$ & $13429^{\mathrm{a}}$ & $152^{\mathrm{abcd}}$ \\
BSG 0.5\% & $5021^{\mathrm{b}}$ & $15490^{\mathrm{bc}}$ & $182^{\mathrm{bcd}}$ \\
BSG 2.5\% & $8974^{\mathrm{g}}$ & $28740^{\mathrm{g}}$ & $251^{\mathrm{de}}$ \\
Standard error & 169 & 491 & 38 \\
\hline
\end{tabular}

*Different letters indicate significant differences between fractions at $\mathrm{p}<0.05$

\section{$\underline{\text { List of Figures }}$}

Fig. 1. Water Binding Capacity of mixtures of gums (xanthan/BSG) plus native corn flour (A), or native corn starch (B), or extruded flour (C) or pregelatinized starch (D). 
A
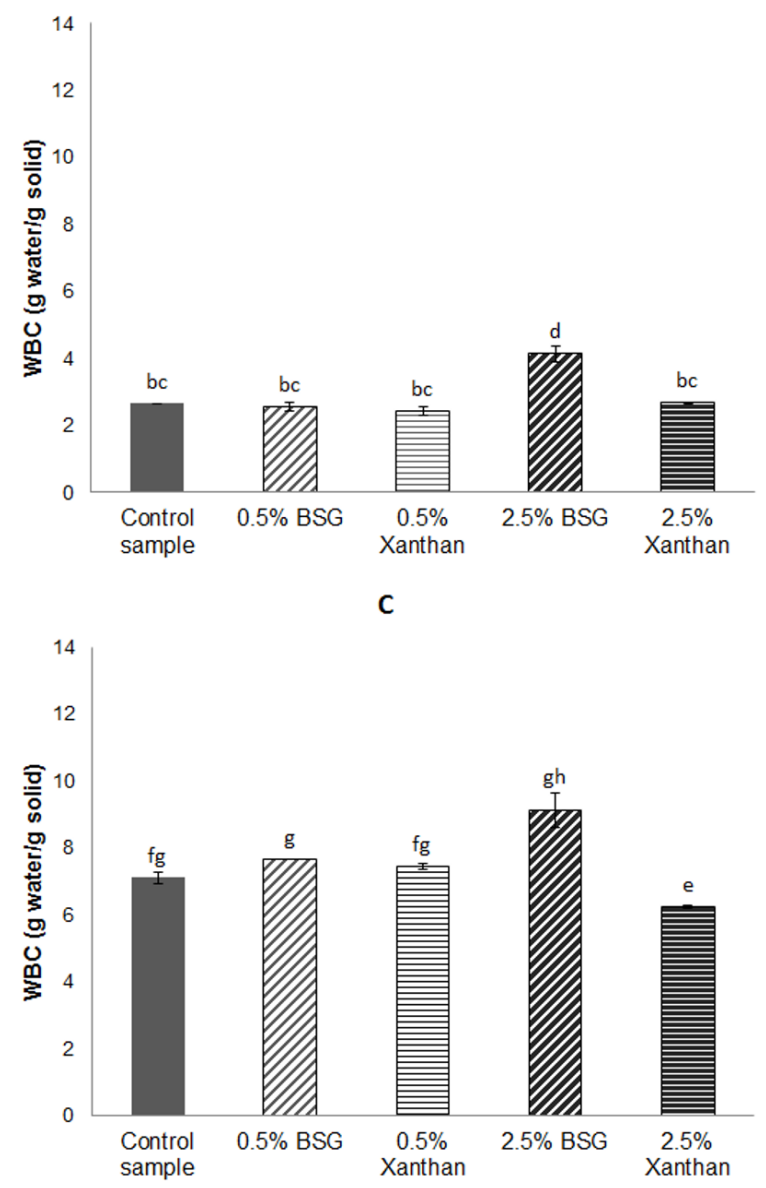

B
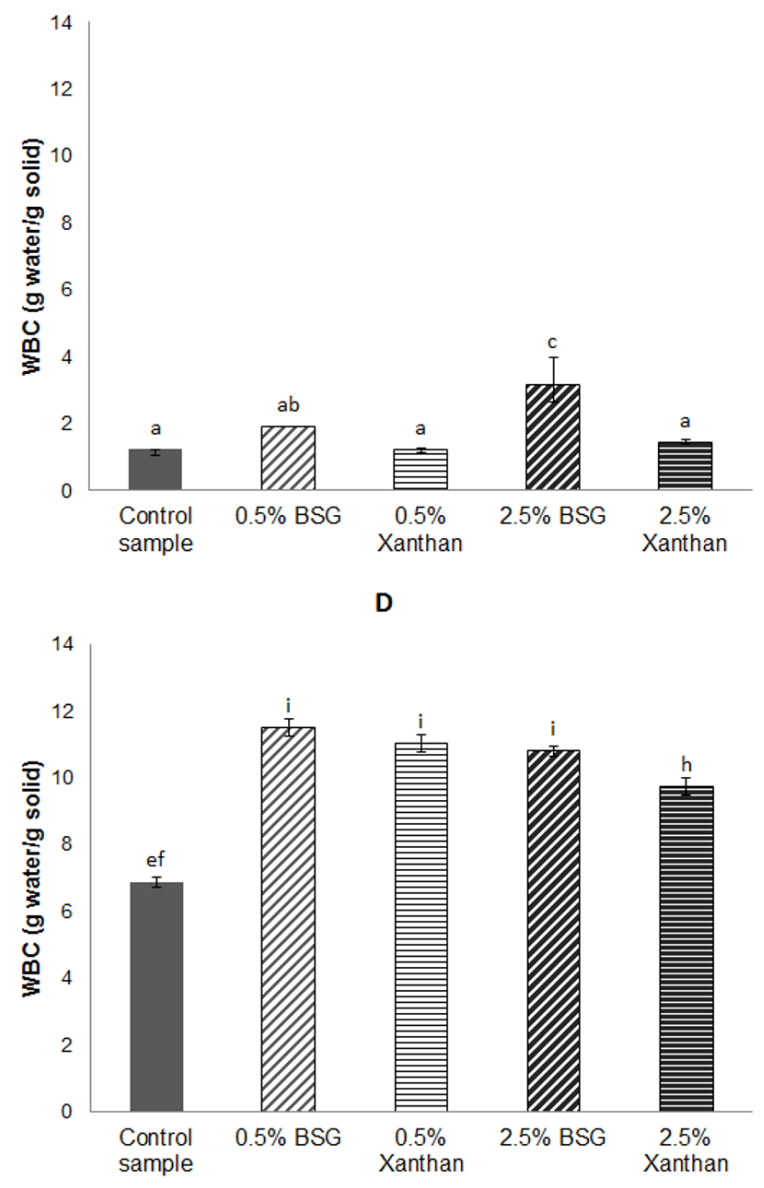
Fig. 2 Water Absorption Index of mixtures of gums (xanthan/BSG) plus native corn flour (A), or native corn starch (B), or extruded flour (C) or pregelatinized starch (D)

A

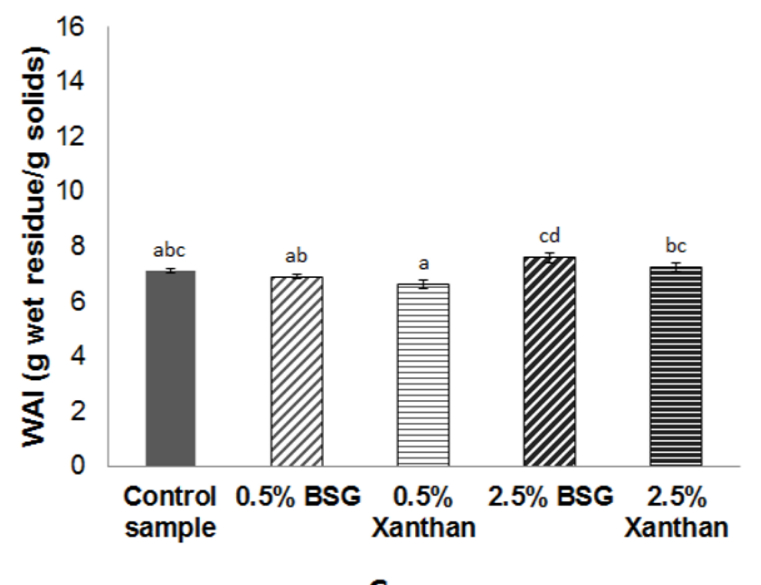

C

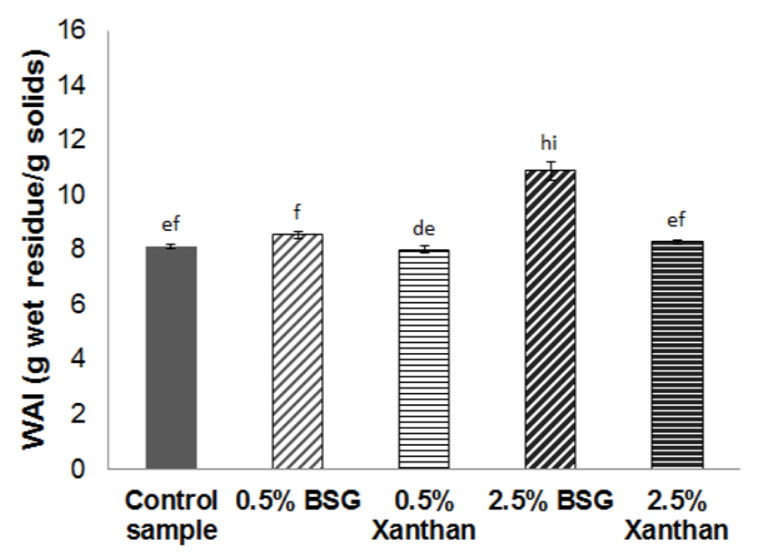

B

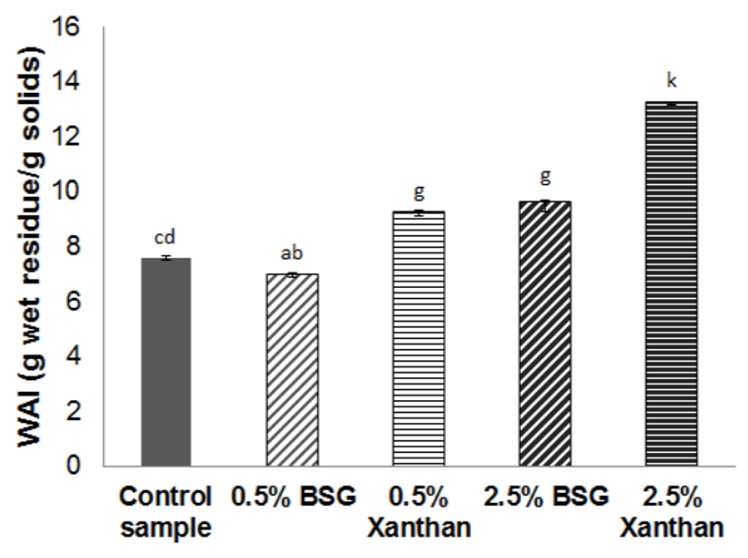

D

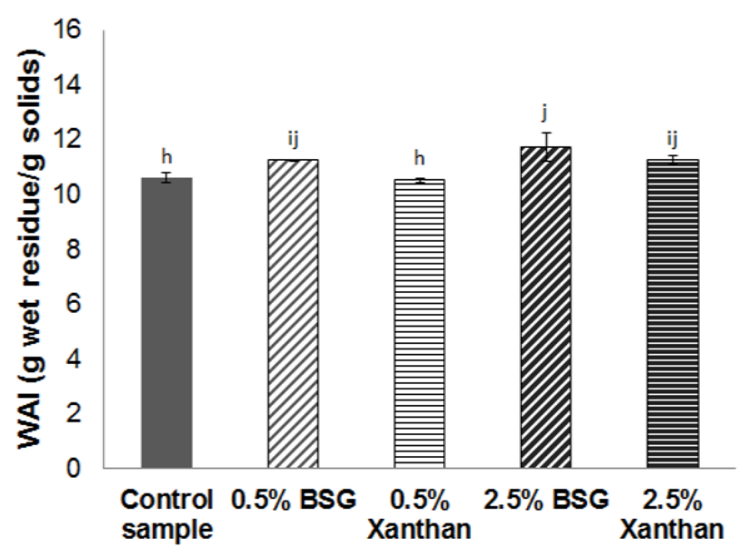


Fig. 3. Pasting Properties of mixtures of gums (xanthan/BSG) plus native corn flour (A), or native corn starch (B), or extruded flour (C) or pregelatinized starch (D).

A

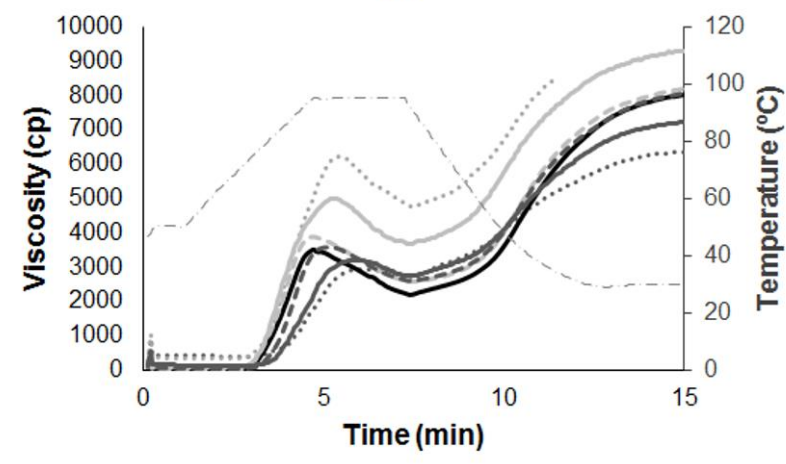

C

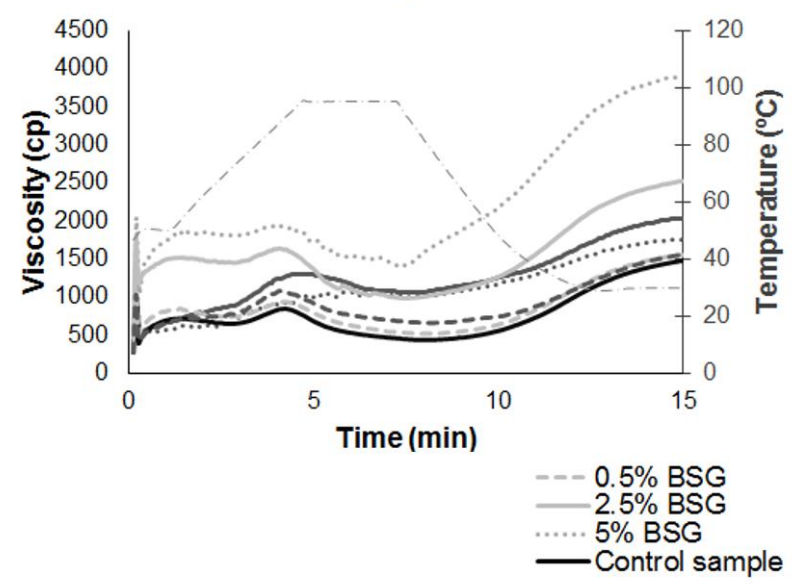

B

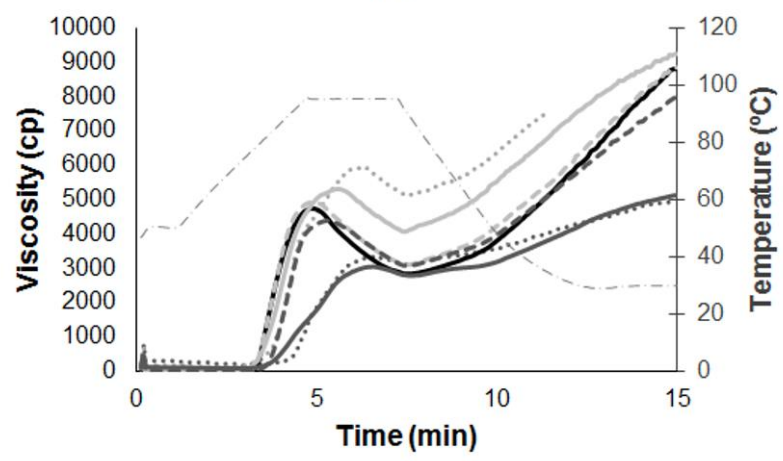

D

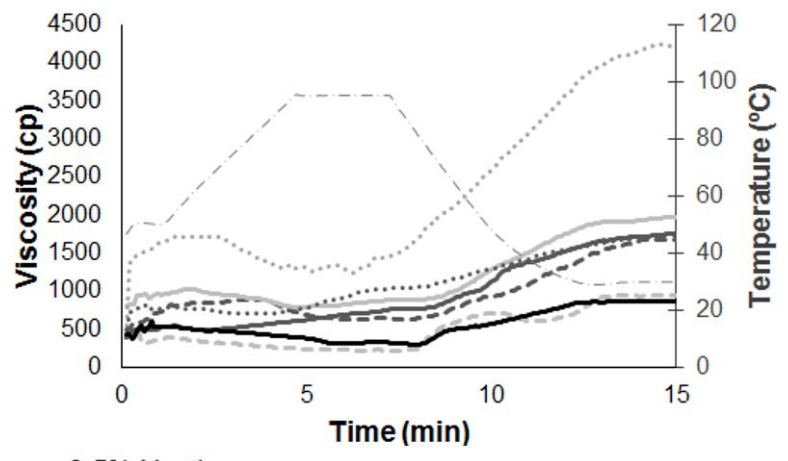

$---0.5 \%$ Xanthan

$-2.5 \%$ Xanthan

...... $5 \%$ Xanthan 
Fig. 4. Time sweep (A) and Frequency sweep (B) of native corn starch. Complex moduli (G*) at $1 \mathrm{~Hz}$ taken from a frequency sweep tests performed on gels made up of gums and native corn flour (C), or native corn starch (D), or extruded flour (E) or pregelatinized starch (F), at $30^{\circ} \mathrm{C}$.

A

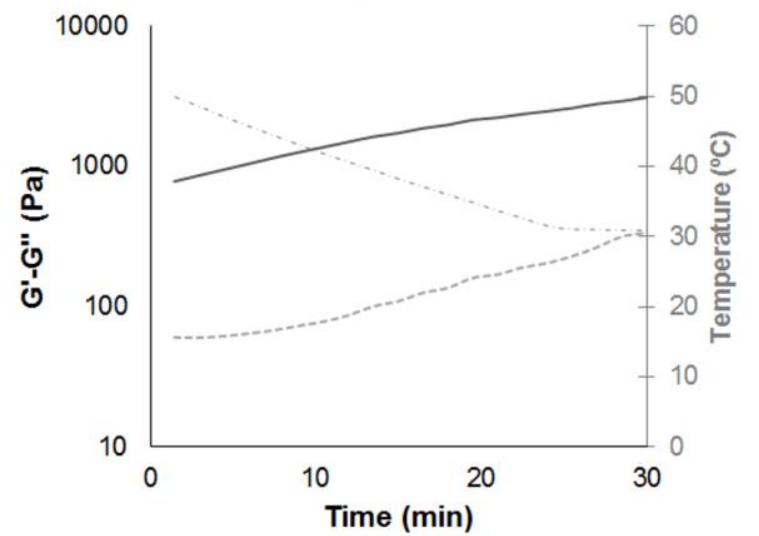

G' Control sample

C
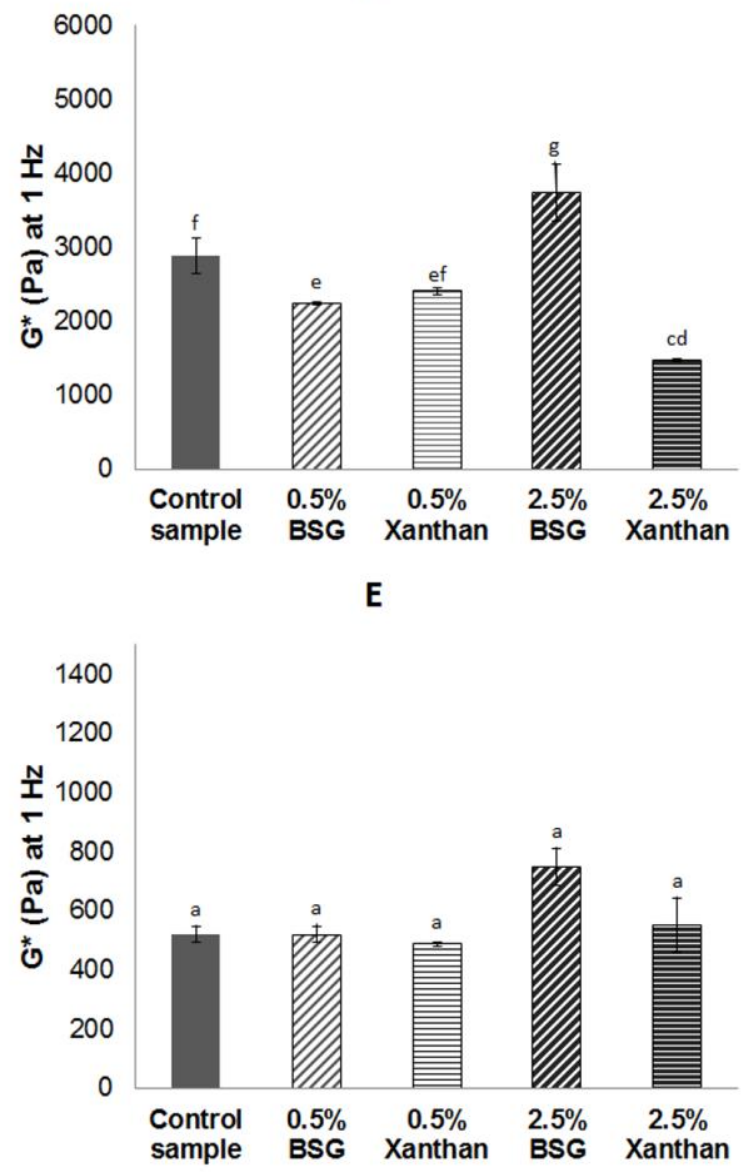

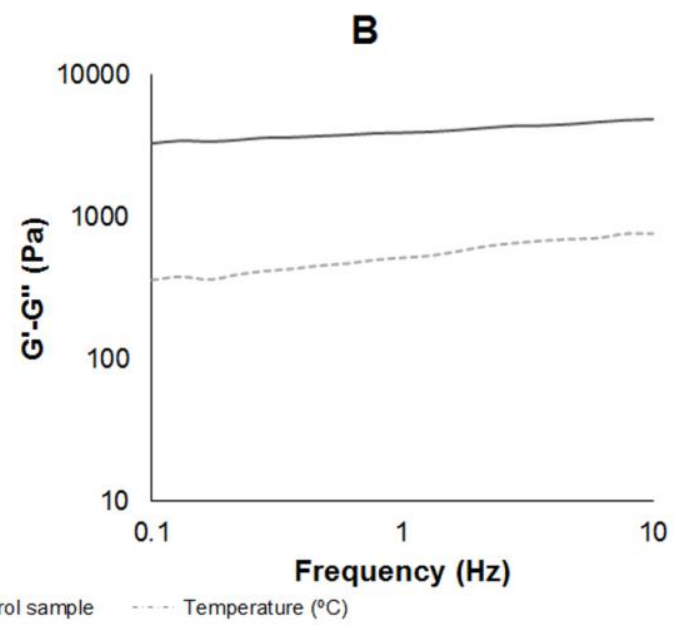

D
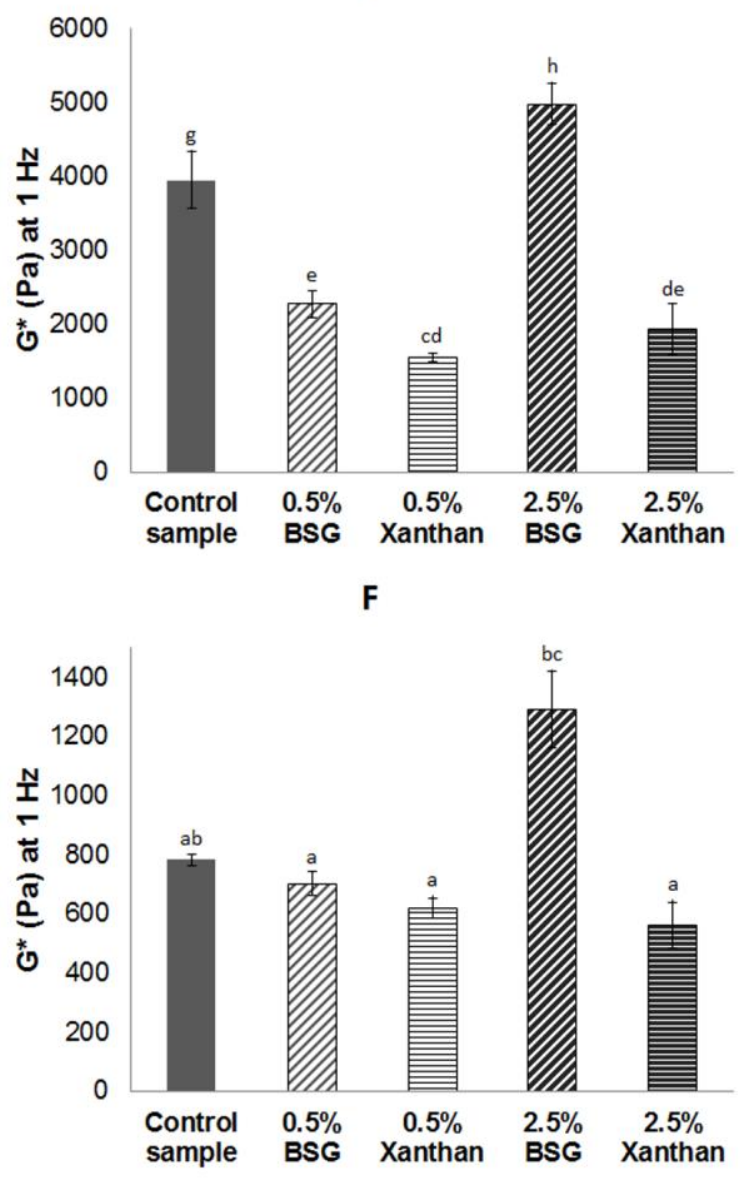
Fig. 5. ESEM micrographs at various magnifications of gels prepared with native corn starch only $(A, B)$, mixed with $2.5 \%$ BSG (D,E,F), or mixed with $2.5 \%$ xanthan (G, H, I). BSG freeze-dried gum only (C). The arrows indicate the BSG spider-like network.

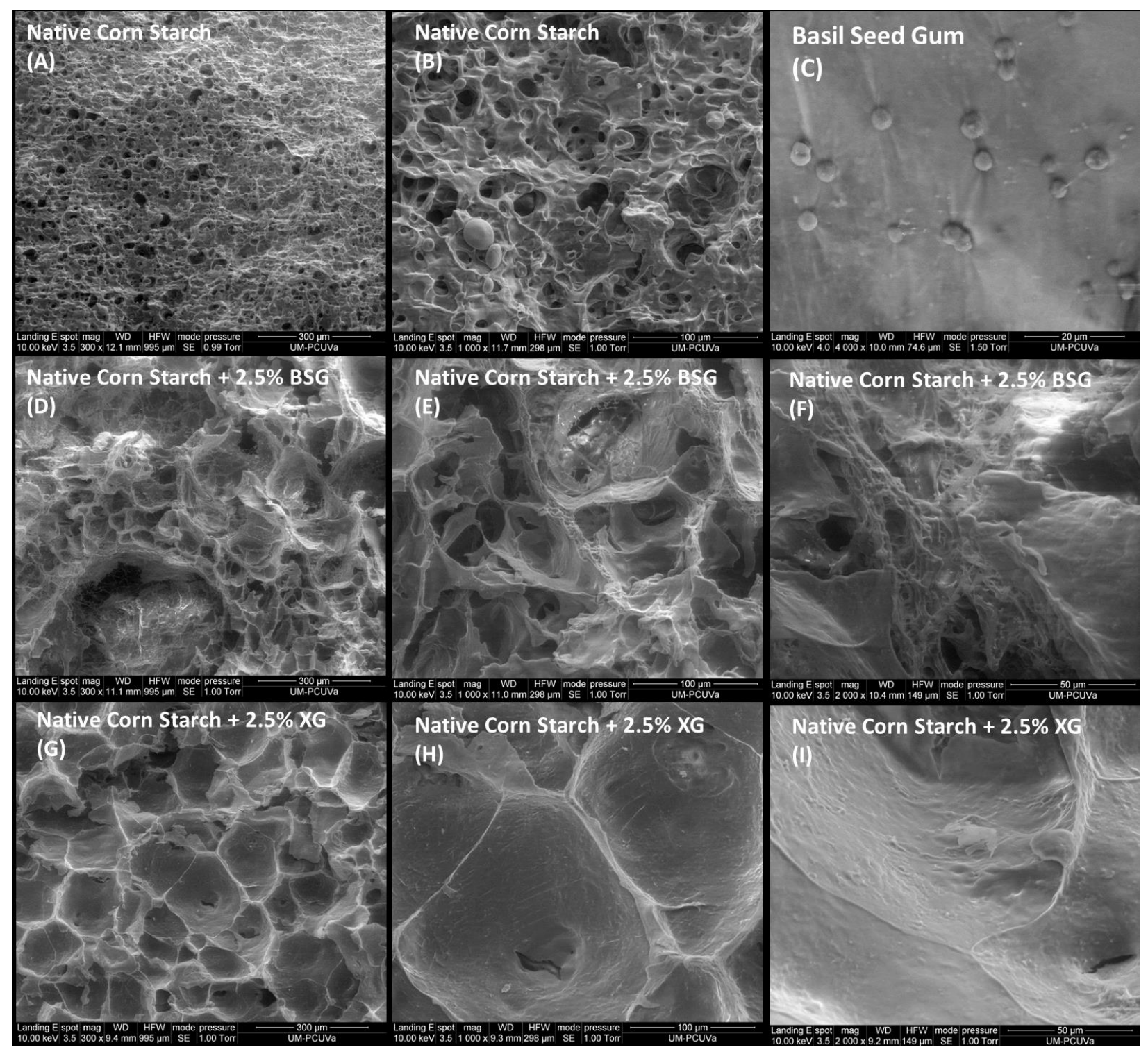

